Palavras chave: Caracterização espectral Dados biofísicos Dosséis

Histórico:

Recebido 03/02/2012 Aceito 28/01/2015

Keywords: Spectral characterization Biophysical data Canopies

Correspondência: sandra@dsr.inpe.br

DOI:
Flávio Jorge Ponzoni', Ludmila Roque Ferraz Pacheco², Sandra Benfica dos Santos', Clódis de Oliveira Andrades Filho ${ }^{3}$

\section{CARACTERIZAÇÃO ESPECTRO-TEMPORAL DE DOSSÉIS DE Eucalyptus spp. MEDIANTE DADOS RADIOMÉTRICOS TM/Landsat5}

RESUMO: Imagens TM/Landsat5 referentes a duas passagens defasadas em um mês (abril e maio de 2009), sobre a região de Capão Bonito (SP) onde se desenvolvem plantios de Eucalyptus uroplilla, Eucalyptus grandis e uma espécie híbrida entre estas duas, foram utilizadas na caracterização espectral de dosséis que apresentavam diferenças estruturais explicadas por diferenças de idade. Essas imagens foram convertidas para valores físicos (Fatores de reflectância de superfície) e, a partir delas, foram geradas outras imagens fruto da aplicação da técnica de principais componentes. As dispersões dos valores de $\mathrm{PCl}$ e de $\mathrm{PC2}$, em um espaço bidimensional, foram avaliadas visando a identificar tendências na dispersão desses valores provenientes dos diferentes dosséis, associadas às suas características biofísicas. Os resultados indicaram que em plantios jovens (até os 3 primeiros anos de idade), a nuvem de dispersão se posiciona nas porções mais inferiores do espaço PCI x PC2 e mais distantes de sua origem (zero). Isso indica maior participação das porções inferiores dos dosséis menos brilhantes na região do infravermelho próximo (solo exposto ou galhos secos) e mais brilhantes na região do visível. Os plantios mais maduros tendem a priorizar participação das folhas em detrimento das porções mais sombreadas, localizadas nas regiões mais inferiores dos dosséis. A caracterização espectral dos dosséis de eucalipto foi consistente nas duas oportunidades aqui exploradas (duas passagens).

\section{SPECTRO-TEMPORAL CHARACTERIZATION OF Eucalyptus spp. CANOPIES BY TM/Landsat 5 RADIOMETRIC DATA}

ABSCTRACT: TM/Landsat 5 images (April and May 2009) from Capão Bonito (SP) region where Eucalyptus urophilla, Eucalyptus grandis and a hybrid of both species have been planted were utilized in the spectral characterization of some stands that presented structural differences explained mainly by age. These images have been converted to physical values such as surface reflectance factors and from these values principal components images were generated. The dispersion of $\mathrm{PCl}$ and $\mathrm{PC} 2$ on a bi-dimensional space has been evaluated to identify tendencies of pixels positioning. Results have shown that for young eucalyptus canopies (up to 3 years old) the positioning is well defined, occupying the lower part of the dispersion clouds and far from the graph origin (zero). This result indicates more participation of the lower portions of the canopies, which presents lower values of reflectance in the near infrared (bare soil or dry branches) and high reflectance in the visible region. The older canopies presented higher influence of photosynthetic active leaves rather than the shadowed and lower portions of the canopies. The spectral characterization of eucalyptus canopies at the two temporal set of data was consistent.

I Instituto Nacional de Pesquisas Espaciais - São José dos Campos, São Paulo, Brasil

${ }^{2}$ Agn Agroindustrial e Biocombustivel LTDA - Campinas, São Paulo, Brasil

${ }^{3}$ Universidade Estadual do Rio Grande do Sul - São Francisco de Paula, Rio Grande do Sul, Brasil 


\section{INTRODUÇÃO}

Uma das principais expectativas entre os usuários de dados de sensoriamento remoto é a associação das características espectrais de objetos com suas propriedades físico-químicas. De fato, tal associação é o fundamento da aplicação das técnicas de sensoriamento remoto, o que torna a referida expectativa cabível e aceitável. Contudo, essa associação está longe de ser considerada trivial, uma vez que o processo de interação da radiação eletromagnética com os objetos é, normalmente, expresso por apenas uma variável radiométrica, frequentemente fatores de reflectância. Estes, segundo Ponzoni et al. (20I2), são explicados pela ação de diferentes fatores, incluindo os já mencionados físico-químicos dos objetos, bem como os geométricos de iluminação (fonte de radiação, normalmente o Sol) e visada (sensor responsável pelo registro da intensidade da radiação refletida pelos objetos). Esse caráter ambíguo da intensidade da radiação eletromagnética refletida pelos objetos fragiliza as caracterizações espectrais desejadas, em razão do acréscimo do grau de incerteza sobre os fatores que, efetivamente, explicam os valores dos fatores de reflectância medidos nos diferentes níveis de coleta possíveis, quer seja em laboratório, em campo, em nível de aeronave ou orbital (PONZONI et al., 20I2).

Nas caracterizações espectrais da cobertura vegetal, por exemplo, as expectativas se concentram na identificação florística da composição de dosséis de diferentes fitofisionomias, na própria caracterização estrutural ou fisionômica, na quantificação de biomassa e/ ou de outros parâmetros dendrométricos, nas estimativas de índices de área foliar e na consequente produtividade (no caso de culturas agrícolas), na estimativa de parâmetros arquitetônicos/estruturais de dosséis florestais etc (CANAVESI, 2008; CANAVESI et al., 2010).

Em todas essas iniciativas envolvendo abordagens empíricas (modelos de regressão ou correlação) ou físicas (modelos de transferência radiativa), como fizeram Campos (2008), Foody et al. (2003), Houborg et al. (2007) e Schlerf e Atzberger (2006), além de outros, depara-se com o caráter ambíguo da reflectância dos dosséis vegetais. Essa ambiguidade, aliada à questão temporal, torna a caracterização espectral da vegetação uma tarefa complexa e que exige a observação cuidadosa de detalhes nem sempre explícitos, mesmo para um profissional experimentado.

Neste trabalho, objetivou-se apresentar e discutir alguns aspectos relevantes da caracterização espectral de plantios de Eucalyptusspp. (eucalipto), mediante ao emprego de dados do sensor orbital TM/ Landsat5 em duas oportunidades no tempo.

\section{MATERIAL E MÉTODOS}

\section{Área de estudo e coleta de dados em campo}

A área de estudo compreendeu plantios de eucalipto localizados no município de Capão Bonito (SP), entre as latitudes $23^{\circ} 46^{\prime} 30^{\prime \prime}$ e $24^{\circ}$ I'26" Sul e as

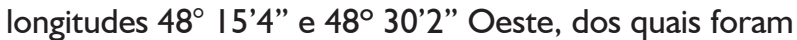
considerados 25 talhões de diferentes idades, procurando obter dados de dosséis com características estruturais díspares, sendo que a coleta de dados em campo foi realizada entre 4 e 8 de maio de 2009. Na Figura I, ilustra-se a localização da área de estudo.

\section{Área de Estudo - Unidade Florestal de Capão Bonito}

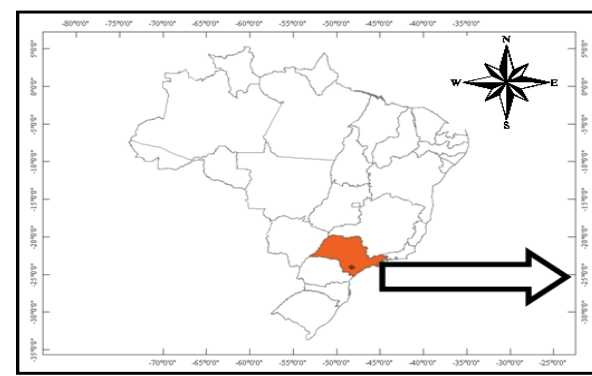

Imagem: LANDSAT TMS Projeção: Geográfica (Latitude/Longitude) Datum: WGS84

Composição colorida: RGB (432) Ano: 2009

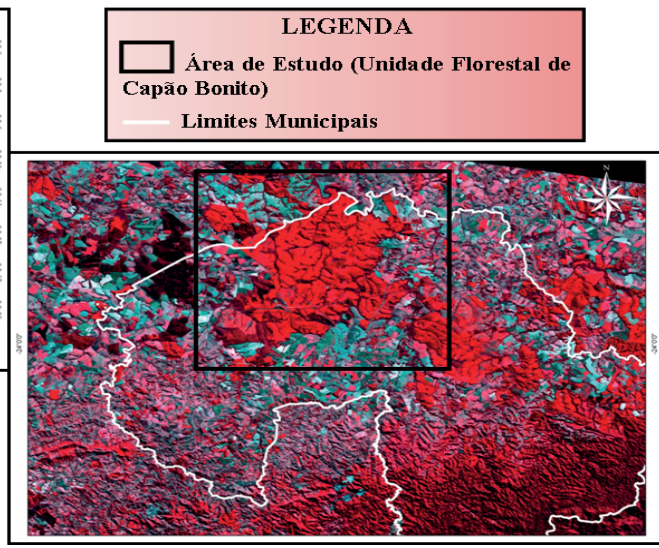

FIGURA 1 Localização geográfica da área de estudo: Unidade Florestal de Capão Bonito.

FIGURE 1 Geographic localization of the study area: Capão Bonito Forest Unit. 
Em cada um dos 25 pontos visitados em campo, foram coletados dados de Diâmetro a Altura do Peito $(D A P)$, Altura total $(H)$, Altura do tronco $(H t)$, Raio da Copa $(R c)$ e Densidade de cobertura do dossel $(D)$. Os parâmetros dendrométricos (DAP, $\mathrm{H}, \mathrm{Ht}$ e Rc) foram coletados de 10 árvores subsequentes, localizadas em uma mesma linha de plantio. A escolha da primeira árvore a ser medida dentro do talhão foi arbitrária, cuja localização era registrada mediante a utilização de um aparelho GPS (Global Positioning System). Procurou-se proceder essa escolha, priorizando árvores localizadas longe de bordas de talhões, para evitar contaminação do efeito de borda.

As medidas de DAP foram tomadas, mediante à utilização de fita diamétrica, enquanto nas medidas de $H$ e de $H t$ utilizou-se um hipsômetro com escala de 20 $m$ de distância. Os valores da Altura da Copa $(\mathrm{Hc})$ foram determinados, a partir das diferenças entre os valores de $\mathrm{H}$ e de $\mathrm{Ht}$. Todos os parâmetros supracitados foram representados, então, pelas médias dos valores das 10 árvores. Os valores de $D$ foram estimados mediante à utilização de um Densitômetro, conforme descrito por Souza (2009) e serviram para estimar percentagem de cobertura das copas nos talhões.

\section{Imagens orbitais}

Foram selecionadas imagens do sensor TM/ Landsat-5 da órbita/ponto 220/77, em seis bandas espectrais que abrangem as regiões do visível (bandas I, 2 e 3), infravermelho próximo (banda 4) e infravermelho médio (bandas 5 e 7) e em duas datas diferentes, em datas definidas o mais próximas possível das datas de coletas de dados em campo, quais sejam 22/04/2009 e 24/05/2009. A escolha dessas duas imagens com passagens (datas) relativamente próximas é explicada pelo fato de que se pretendia minimizar o tempo entre a coleta de dados em campo e a disponibilidade de dados orbitais. Assim, estaríamos trabalhando com duas imagens, cujos dados coletados em campo poderiam ser utilizados na análise da caracterização espectral (parâmetros biofísicos, influenciando os dados radiométricos presentes nas imagens) em ambas as oportunidades. Ao mesmo tempo, seria possível comparar as caracterizações espectrais ao longo do tempo, considerando fundamentalmente que as maiores alterações estariam acontecendo na geometria de iluminação entre as passagens.

Para que as imagens pudessem ser comparadas ao longo do tempo e as caracterizações espectrais fossem viabilizadas, primeiramente os números digitais
(NDs) das imagens das duas datas em questão foram convertidos para valores de fatores de reflectância aparente mediante a aplicação das equações I e 2, sendo: $r_{\lambda}=$ fator de reflectância aparente; $L_{\lambda}=$ radiância no topo da atmosfera na faixa espectral $\lambda ; d=$ distância TerraSol em unidades astronômicas; Esun $_{\lambda}=$ Irradiância solar no topo da atmosfera na faixa espectral $\lambda ; q_{s}=$ ângulo zenital solar no horário de aquisição da imagem.

$\rho_{\lambda}=\frac{\pi \cdot L_{\lambda} \cdot d^{2}}{\operatorname{Esun}_{\lambda} \cdot \cos \left(\theta_{s}\right)}$

Os valores de $L_{\lambda}$ foram determinados, mediante à aplicação da equação 2 , sendo: $L_{\lambda}=$ radiância no topo da atmosfera na faixa espectral $\lambda ; \operatorname{Lmax}_{\lambda}=$ radiância máxima quando $Q C A L=Q C A L M A X ; \operatorname{Lmin}_{\lambda}=$ radiância mínima quando $Q C A L=0 ; Q C A L=$ valores de números digitais referentes e proporcionais a $L_{\lambda} ;$ QCALMAX $=$ valor máximo de número digital quando $L_{\lambda}=L \max _{\lambda}$.

$L_{\lambda}=\left(\frac{L \max _{\lambda}-L \min _{i}}{Q C A L M A X}\right) Q C A L$

Os valores de $L \max _{\lambda}$ e de $L \min { }_{\lambda}$ foram extraídos de Chander et al. (2009), segundo as datas das imagens utilizadas.

Vale salientar que a aplicação dessas equações I e 2 consideram que os pixels na imagem estão dispostos em uma superfície horizontal e plana, desconsiderando, então, seu posicionamento topográfico caracterizado pela declividade e pela exposição (orientação em relação ao norte geográfico). Segundo Hay (1993), a radiância medida pelo sensor em órbita é proporcional ao cosseno do ângulo de incidência $\cos \left(r t^{\wedge} r s\right)$, que é $\circ$ ângulo entre a normal, a superfície e o vetor solar (Equação 3, sendo: $r t$ e $r s=$ vetores direcionais, terreno e iluminação respectivamente; $\theta \mathrm{s}=$ ângulo zenital solar; $\theta \mathrm{t}=$ declividade; $\psi \mathrm{s}=$ ângulo azimutal solar; $\psi \mathrm{t}=$ imagem azimute/orientação da vertente).

$\cos \left(r t^{\wedge} r s\right)=\cos (\theta s) \times \cos (\theta t)+\operatorname{sen}(\theta s) \times \operatorname{sen}(\theta t) \times$ $\times \cos (\psi s-\psi t)$

Essa Equação 3, tem sido utilizada por Valeriano (2006) em estimativas de valores de radiância aparente, a partir de dados orbitais. Canavesi (2008) serviu-se dessa Equação 3 para a geração de "Classes de lluminação" que serviram para fragmentar uma imagem do sensor TM/Landsat 5, na caracterização espectral de plantios de Eucalyptus sp. Essa mesma estratégia foi adotada neste trabalho para atingir o mesmo objetivo. 
Optou-se por utilizar $\cos \left(\mathrm{q}_{\mathrm{s}}\right)$, ao invés de $\cos \left(r t^{\wedge} r s\right)$ na Equação I, com o objetivo de tornar a estratégia de conversão de dados mais simples e familiar à maioria dos usuários de imagens orbitais. Nada impede que $\cos \left(r t^{\wedge} r s\right)$ seja substituído por $\cos \left(q_{s}\right)$, no cálculo dos fatores de reflectância aparente.

Em seguida, as imagens convertidas para valores de fator de reflectância aparente foram, então, submetidas ao procedimento de correção atmosférica, mediante à aplicação do modelo Second Simulation of the Satellite Signal in the Solar Spectrum (6S) de transferência radiativa (VERMOTE et al., 1997), visando a sua conversão para valores de fator de reflectância de superfície $\left(r_{s}\right)$. As imagens resultantes foram mantidas em 8 bits (256 níveis de cinza).

Para a correção atmosférica das duas cenas, foram adotados o modelo atmosférico tropical, o tipo de aerossol continental e a visibilidade de $50 \mathrm{~km}$, uma vez que ambas as imagens apresentavam nível similar de nitidez e não se dispunha de qualquer outra informação que permitisse melhor caracterização da atmosfera em ambas as passagens do satélite sobre a área de estudo.

\section{Elaboração das imagens Principais Componentes (PC)}

Foram geradas, então, 6 novas imagens PC para cada uma das duas passagens (22/04/2009 e 24/05/2009), utilizando-se as imagens convertidas para fator de reflectância de superfície escalonadas em 8 bits. Dessas 6 novas imagens, foram apenas aproveitadas as duas primeiras imagens PC de cada passagem, com o objetivo de permitir a definição de um espaço bidimensional explorado por Crist e Cicone (1984), no qual a primeira principal componente $(\mathrm{PCI})$ equivale àquilo que se denomina "brigthness" e a segunda principal componente (PC2) que se denomina "greeness". A análise do posicionamento dos pixels provenientes dos dosséis de eucalipto, dentro deste espaço bidimensional, permite, então, extrair informação sobre algumas de suas propriedades biofísicas, como veremos a seguir.

Uma vez que foram considerados apenas dados provenientes de pixels ocupados por dosséis de eucalipto, ou seja, por vegetação, no espaço bidimensional explorado por Crist e Cicone (1984) a análise dos resultados incluirá aspectos como ilustrado na Figura 2. Nessa Figura 2, o eixo $X$ representa $\mathrm{PCI}$, ou seja, ele contém dados relativos a "brightness", algo que poderia ser interpretado de forma análoga aos dados provenientes de alguma imagem da região do visível. Nesse eixo $X$, portanto, valores inferiores representariam pixels ocupados por sombra, água ou por vegetação fotossinteticamente ativa (Ponzoniet al. 20I2). O eixo Y representa PC2 é denominado "greeness", ou seja, análogo à região espectral do infravermelho próximo, região esta, na qual a vegetação reflete grande parte da radiação incidente. Assim, valores inferiores em PC2 indicariam também sombra ou água, enquanto valores superiores indicariam presença de vegetação densa e livre de sombras, ou seja, vegetação "pura”.

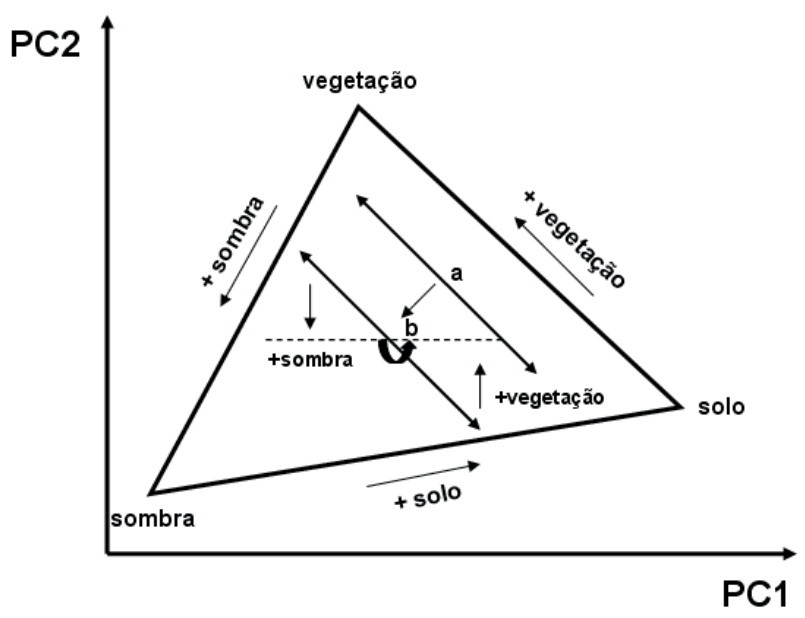

FIGURA 2 Espaço bidimensional explorado por Crist e Cicone (1984) sobre o qual se fundamentarão as análises dos dados.

FIGURE 2 Bi-dimensional space explored by Crist and Cicone (1984) under which data analysis will be based on.

A distribuição dos fatores de reflectância de superfície de uma cena qualquer define, nesse espaço bidimensional limitado pelos eixos $\mathrm{PC} 2$ e $\mathrm{PCI}$, uma figura geométrica semelhante a um triângulo em cujos vértices encontramos os chamados elementos "puros" de vegetação, de sombra ou água e de solo ou galhos secos. Algum ponto localizado exatamente no centro desse triângulo indicaria que a natureza físico-química do objeto, no interior desse ponto ou pixel incluiria proporções igualitárias de vegetação, água ou sombra e de solo ou galhos secos. Alguma trajetória em suas bordas indicaria o aumento ou a diminuição de cada um desses elementos dentro do pixel.

Como tratamos exclusivamente de pixels provenientes de dosséis de eucalipto de diferentes idades e de, basicamente, três espécies (Eucalyptus grandis, Eucalyptus urophilla e outra híbrida entre ambas), espera-se que seus posicionamentos se restrinjam às proximidades da reta "a" identificada na Figura 2. Assim, os pixels provenientes dos dosséis de eucalipto serão 
compostos por mais ou menos vegetação (basicamente folhas verdes), sombras e solo ou galhos secos, dependendo de suas estruturas que deverão variar em função da idade e da procedência genética. Como estamos ainda nos servindo de dados de duas datas diferentes (defasagem de um mês em relação à data de coleta de dados em campo), espera-se que a variação da geometria de iluminação exerça, também, alguma influência no posicionamento dos pixels dos dosséis de eucalipto, considerando que não houve alteração significativa da estrutura dos dosséis em apenas um mês.

Ainda, na Figura 2, pode-se observar que algum deslocamento da posição "a" para "b" indicaria que os dosséis estariam perdendo brilho por acréscimo da quantidade de sombras no interior do dossel, enquanto que alguma rotação do eixo (para a posição indicada pelo eixo tracejado) poderia ser interpretada por ganhos e perdas de sombras e da participação de solo ou galhos secos.

\section{Identificação de classes de iluminação}

Considerando que a área de estudo localizase em região com relevo ligeiramente ondulado, decidiu-se identificar, em cada uma das datas nas quais foram adquiridas as imagens TM/Landsat 5, classes de iluminação no terreno de forma a permitir a extração de valores de fator de reflectância de superfície dos dosséis, conhecendo-se qual o nível de iluminação que os explicava. Assim, a partir de dados topográficos da área de estudo gerados por Valeriano (2004), na resolução de $90 \mathrm{~m}$, foram adquiridos dados de declividade do terreno e de orientação das vertentes que foram aplicados à Equação 3, cujos resultados serviram de base para a definição das chamadas "Classes de Iluminação", assim como fez Canavesi (2008).

Vale salientar que a fragmentação da imagem em classes de iluminação foi feita apenas com os dados de declividade, de exposição e de posicionamento solar para o horário de obtenção da imagem utilizada. Os valores dos fatores de reflectância de superfície da imagem resultante do processo de correção atmosférica foram utilizados na caracterização espectral dos dosséis em cada classe de iluminação como se verá a seguir.

Decidiu-se definir as classes de iluminação, observando os valores máximos e os valores mínimos dos parâmetros que variam no cálculo da equação, como a declividade e a orientação das vertentes. A partir da observação dessa variação, combinações foram feitas com esses valores, para análise da amplitude das classes. Para isso, foram considerados os dados máximos e mínimos de declividade e de orientação de vertente da área de estudo. Os limites de classes de declividade propostos pela Empresa Brasileira de Pesquisa Agropecuária - EMBRAPA (1999) foram adotados, sendo que as classes encontradas na região foram: plana, suave ondulada, ondulada, forte ondulada e montanhosa. A imagem orientação das vertentes foi dividida em quatro classes, sendo as vertentes orientadas para o norte mais iluminadas. As classes definidas foram: NE - SE (nordeste-sudeste); SE-SO (sudeste-sudoeste); SO-NO (sudoeste-noroeste); NONE (noroeste-nordeste). Tais classes foram escolhidas, partindo-se do pressuposto de que vertentes voltadas para o sul estão sujeitas a menor exposição à radiação solar, enquanto que as vertentes voltadas para o norte estão mais expostas e as demais direções estão sujeitas a condições intermediárias de iluminação. A partir das classes de declividade e das classes de orientação das vertentes às combinações, foram estabelecidas as seguintes classes de iluminação: Iluminado: plantios localizados em regiões planas onde a interferência da vertente é nula, e a radiação estaria chegando de maneira uniforme; Pouco iluminado: plantios localizados em regiões destacadas com vertentes opostas à direção de iluminação solar, com terreno inclinado, recebendo, dessa forma, apenas a radiação difusa; Muito iluminado: plantios localizados em regiões com vertentes voltadas á Norte com relevo inclinado, recebendo, assim, a radiação direta.

\section{Extração de dados das imagens PC e Fator de reflectância de superfície}

A partir do mapeamento das classes de iluminação gerado para as imagens das duas datas, foram identificadas, para cada um dos 25 pontos visitados em campo, as classes de iluminação no momento da passagem do satélite sobre a área de estudo. Isso serviu para auxiliar a extração dos valores dos níveis digitais das imagens PC e dos valores de fatores de reflectância de superfície das imagens convertidas em cada ponto. Essa extração foi realizada, levando em consideração a coordenada geográfica registrada em campo e a classe de iluminação correspondente em cada data.

Esses dados extraídos, foram organizados na forma gráfica, a partir dos quais foram efetuadas as análises pretendidas. 


\section{RESULTADOS E DISCUSSÃO}

\section{Dados dendrométricos}

$\mathrm{Na}$ Tabela I, apresentam-se os dados dendrométricos coletados em campo.

TABELA 1 Dados dendrométricos coletados entre os dias 0408 de maio de 2009.

TABLE 1 Biophysical data collected between 04-08 of May, 2009.

\begin{tabular}{|c|c|c|c|c|c|c|c|}
\hline Ponto & $\begin{array}{l}\text { DAP } \\
(\mathrm{cm})\end{array}$ & $\begin{array}{l}\mathrm{H} \\
(\mathrm{m})\end{array}$ & $\begin{array}{l}\mathrm{Ht} \\
(\mathrm{m})\end{array}$ & $\begin{array}{l}\mathrm{Hc} \\
(\mathrm{m})\end{array}$ & $\begin{array}{l}\mathrm{Rc} \\
(\mathrm{m})\end{array}$ & $\begin{array}{c}D \\
(\%)\end{array}$ & $\begin{array}{l}\text { Idade } \\
\text { (anos) }\end{array}$ \\
\hline 3 & 17,00 & 24,90 & 21,75 & 4,35 & 1,14 & 81 & 6 \\
\hline 4 & 17,83 & 25,65 & 21,45 & 4,20 & 1,20 & 65 & 6 \\
\hline 5 & 11,71 & 14,90 & 8,15 & 6,75 & 1,05 & 95 & 2 \\
\hline 6 & 11,92 & 13,73 & 7,55 & 6,18 & 1,27 & 91 & 2 \\
\hline 7 & 16,55 & 25,45 & 22,45 & 3,00 & 1,22 & 82 & 6 \\
\hline 8 & 16,11 & 23,45 & 20,10 & 3,35 & 1,19 & 72 & 5 \\
\hline 9 & 14,61 & 20,85 & 14,10 & 6,75 & 1,18 & 91 & 3 \\
\hline 10 & 14,07 & 18,65 & 14,55 & 4,10 & 1,21 & 89 & 3 \\
\hline 11 & 14,61 & 24,60 & 21,40 & 3,20 & 1,14 & 83 & 6 \\
\hline 12 & 15,06 & 22,70 & 20,50 & 2,20 & 0,99 & 84 & 6 \\
\hline 14 & 13,18 & 16,10 & 11,30 & 4,80 & 1,15 & 84 & 3 \\
\hline 15 & 16,23 & 22,75 & 17,90 & 4,85 & 1,05 & 75 & 4 \\
\hline 16 & 16,81 & 23,80 & 20,60 & 3,20 & 1,13 & 88 & 4 \\
\hline 17 & 20,18 & 26,25 & 20,65 & 5,60 & 1,17 & 84 & 8 \\
\hline 18 & 24,99 & 29,55 & 21,10 & 8,45 & 1,23 & 83 & 9 \\
\hline 19 & 9,45 & 9,75 & 2,40 & 7,35 & 1,53 & 96 & 1 \\
\hline 20 & 7,93 & 8,30 & 8,30 & 8,30 & 1,55 & 90 & 1 \\
\hline 21 & 9,74 & 9,05 & 3,05 & 6,00 & 1,48 & 92 & 1 \\
\hline 22 & 10,98 & 11,80 & 5,75 & 6,05 & 1,42 & 91 & 2 \\
\hline 23 & 11,90 & 17,00 & 9,65 & 7,35 & 1,32 & 86 & 2 \\
\hline 24 & 12,03 & 15,90 & 10,65 & 5,25 & 1,35 & 87 & 2 \\
\hline 25 & 13,94 & 17,60 & 12,95 & 4,65 & 1,28 & 84 & 3 \\
\hline 26 & 13,34 & 16,90 & 12,25 & 4,65 & 1,39 & 85 & 3 \\
\hline 28 & 18,14 & 26,65 & 23,70 & 2,95 & 1,28 & 79 & 5 \\
\hline
\end{tabular}

Obs.: destaques em negrito representam valores máximos e mínimos dentro de cada variável dendrométrica.

Os dados apresentados na Tabela I não surpreendem com relação àquilo que seria esperado, ou seja, plantios mais velhos apresentam os maiores valores de DAP, $\mathrm{H}$, enquanto que os mais jovens apresentam os menores valores nesses mesmos parâmetros. Para os parâmetros $\mathrm{Ht}$ e $\mathrm{HC}$, essa tendência é ligeiramente quebrada, mas, ainda, $\mathrm{Ht}$ é menor para plantios mais jovens, enquanto Hc é maior. Para Rc, conforme esperado, os plantios mais velhos tendem a apresentar valores menores do que os mais jovens. Finalmente, os valores de $D$ também não surpreenderam, sendo maiores para plantios mais jovens e quando estes se tornam mais velhos, essa tendência vai se quebrando e assume dependência de outros fatores como espécie, sítio ou clone. Vale salientar que em todos os pontos visitados em campo, os plantios se encontravam com o mesmo espaçamento $(3 \times 2 \mathrm{~m})$.

\section{Caracterização espectral}

Na Figura 3, apresentam-se os resultados da caracterização espectral dos dosséis de eucalipto apresentados na forma gráfica. Vale salientar que optouse por apresentar as escalas em X e em Y em 8 bits (256 níveis de cinza).

A análise desses resultados deve levar em consideração as três classes de iluminação (Muito iluminada, lluminada e Pouco iluminada) para minimizar, tanto quanto possível a interferência do posicionamento topográfico dos dosséis sobre sua caracterização espectral. Assim, nessa Figura 3, temos pares de conjuntos de dados provenientes de mesmas parcelas nas quais houve concordância com as classes de iluminação nas duas passagens do satélite.

O primeiro aspecto que chama a atenção nesses gráficos é a definição de grupos de pixels específicos para cada parcela, ou seja, para cada dossel, quase que individualmente dentro do espaço bidimensional. Evidentemente, observa-se superposição entre vários grupos, mas houve nítida tendência de agrupamento dos dosséis com características estruturais similares. Observa-se, por exemplo, que para as classes Muito iluminada e lluminada houve tendência de os dosséis mais jovens posicionaram-se com valores inferiores em $\mathrm{PC} 2$ e superiores em $\mathrm{PCl}$. Esse posicionamento é indicativo de que desses dosséis estariam dominando em sua reflectância o background (neste caso a liteira) ou os galhos secos presentes sobre o solo ou ainda presos às árvores, em detrimento da participação das folhas verdes. Houve apenas uma exceção para a dispersão dos pontos da parcela 16 (4 anos) que ficou restrita, também, às porções inferiores da nuvem de pontos, indicando que, também, para esse dossel, estaria havendo interferência da liteira ou de galhos secos.

Os demais plantios com idades entre 4 e 6 anos posicionaram-se ora em porções medianas, ora em porções superiores da nuvem de pontos, indicando maior participação das folhas verdes na reflectância do dossel, agora em detrimento da participação das sombras no 
interior dos dosséis ou do background e de galhos secos. Plantios mais velhos, acima dos 6 anos, se posicionaram nas porções mais medianas das nuvens de pontos, indicando perda da influência das folhas verdes e talvez ganho da participação da liteira (incluindo galhos secos depositados sobre o solo), já que esses dosséis apresentam poucos
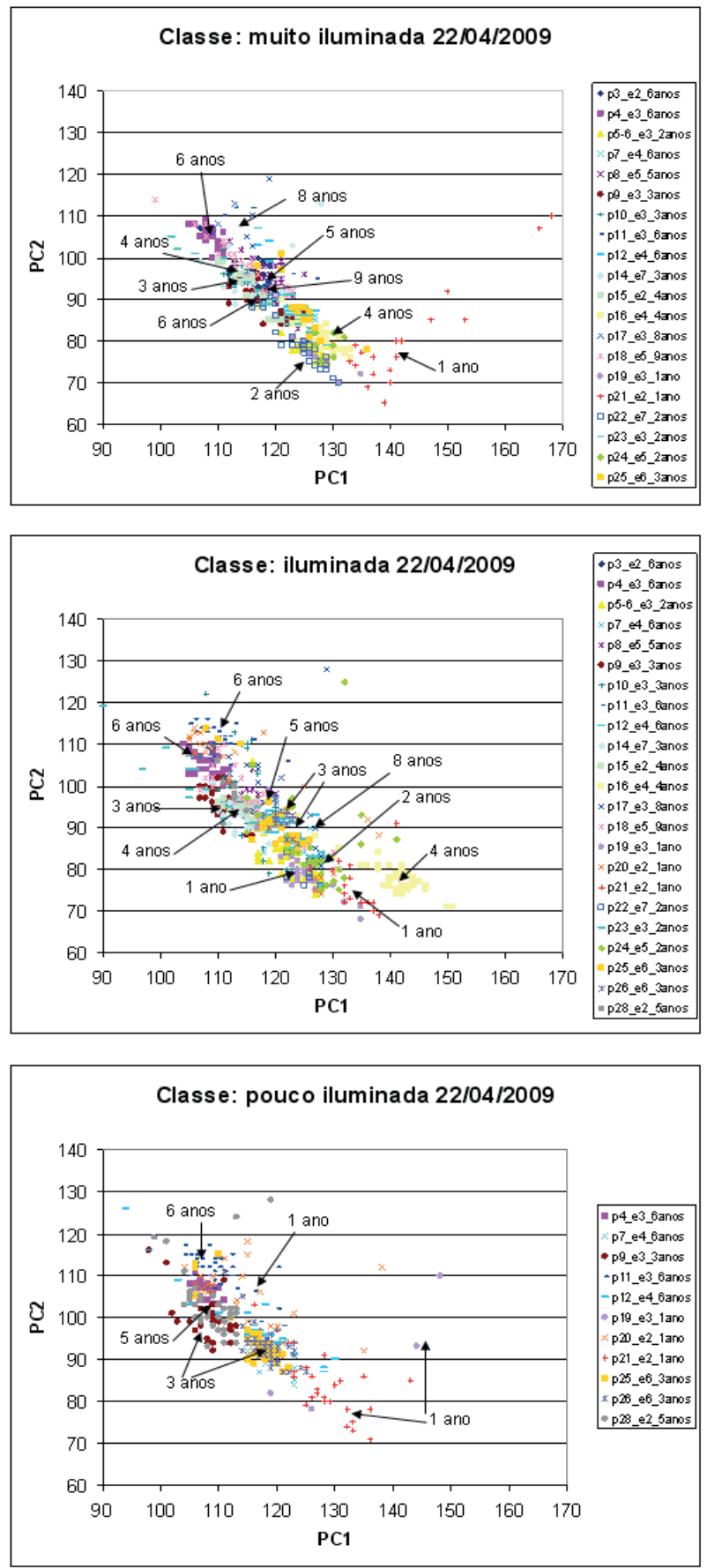

galhos secos presos às árvores. Essas observações são válidas para as três classes de iluminação. Vale lembrar que os dosséis de 8 e 9 anos aqui estudados tinham sido desbastados, o que alterou o espaçamento entre as árvores, provavelmente permitindo, então, maior participação da liteira na reflectância desses mesmos dosséis.
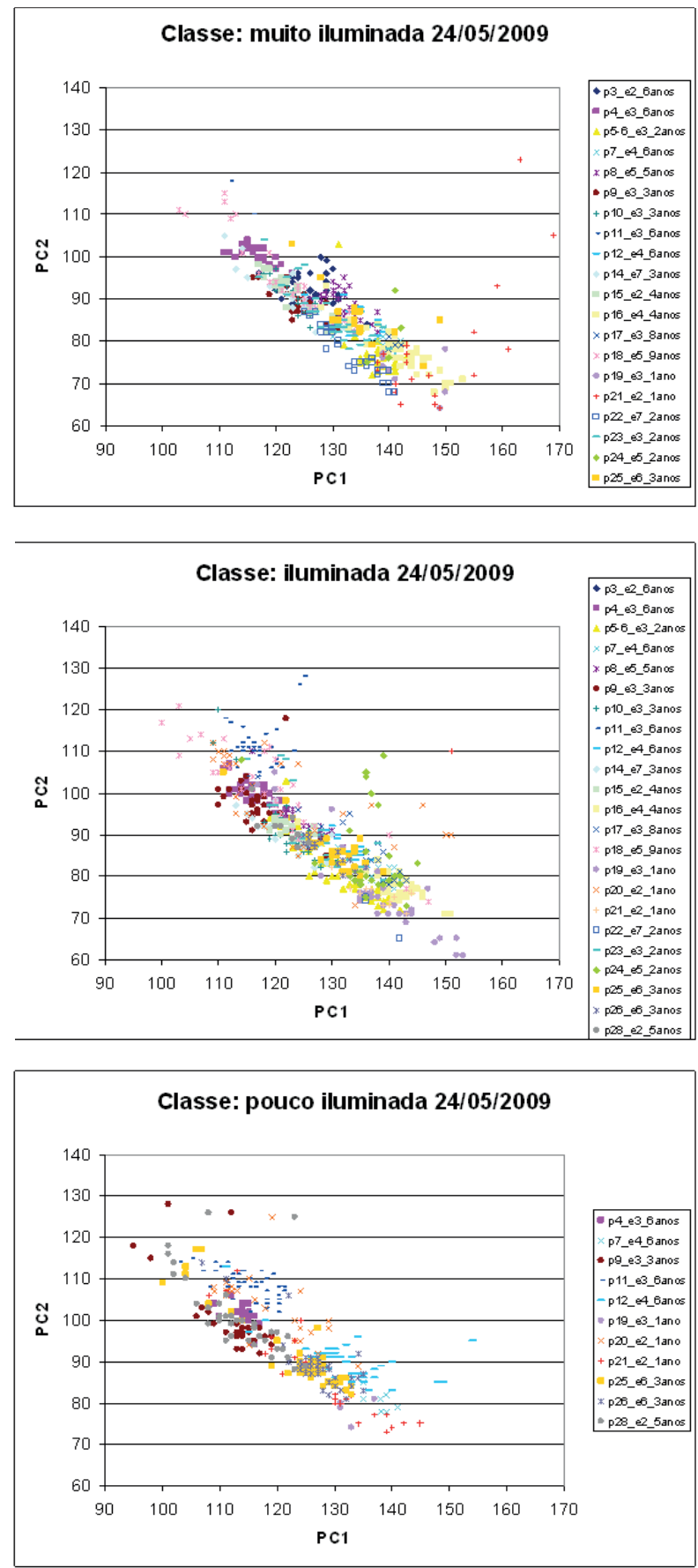

FIGURA 3 Distribuição bidimensional dos valores de PCs dos dosséis de eucalipto.

FIGURE 3 Bidimensional distribution of eucalyptus canopies' PCs. 
Para a classe Pouco iluminada, essa tendência de posicionamento dos plantios mais jovens na porção inferior da nuvem de pontos foi ligeiramente quebrada, com alguns talhões de I e 3 anos, ocupando porções mais superiores da nuvem e outros de 6 anos, ocupando as porções inferiores. Esse resultado é um indicativo de que com iluminação mais oblíqua, esses dosséis mais maduros (6 anos) passam a permitir maior participação das porções inferiores, enquanto que os mais jovens passam a priorizar em sua reflectância a participação das porções superiores (copas).

Outro aspecto interessante refere-se à consistência encontrada no posicionamento relativo dos pixels nas duas datas em questão. Apesar disso, é possível observar alteração, tanto no ângulo médio da dispersão dos dados entre as duas datas, bem como algum deslocamento das nuvens, ao longo do espaço bidimensional definido. Para a classe Muito iluminada ○ ângulo de inclinação da reta variou de $48,3^{\circ}$ para $41,1^{\circ}$ entre as duas datas; de $47,4^{\circ}$ para $43^{\circ}$ para a classe lluminada e finalmente de $47^{\circ}$ para $42^{\circ}$ para a classe Pouco iluminada. Essa rotação é, principalmente, explicada pelo aumento dos valores das PCs dos dosséis mais jovens em $\mathrm{PCl}$ e ligeira diminuição dos valores em PC2 dos dosséis mais velhos. Esse resultado sugere que, para dosséis jovens, a visada solar mais oblíqua privilegia participação da liteira e/ou de galhos na reflectância do dossel, enquanto que para os dosséis mais velhos há aumento da participação das sombras entre folhas ou entre árvores.

\section{CONCLUSÕES}

A caracterização espectral de plantios de eucalipto, elaborada a partir das principais componentes, viabilizou a formulação de algumas hipóteses a respeito, tanto de sua arquitetura quanto dos elementos constituintes dos dosséis que estariam participando mais ou menos em função da geometria de iluminação. Esse comportamento anisotrópico dos dosséis de eucalipto foi evidenciado pela alteração dos posicionamentos das PCs dentro do espaço bidimensional definido entre a primeira e a segunda componente entre as datas e a consistência dos resultados entre as datas conferiu algum grau de confiabilidade à interpretação dos resultados.

O posicionamento dos plantios mais jovens, pelo menos até os 3 primeiros anos, é bem definido dentro do espaço bidimensional, composto pelas duas primeiras componentes principais elaboradas a partir das 6 bandas do espectro óptico do sensor TM/Landsat 5 .
A caracterização espectral dos dosséis de eucalipto foi consistente nas duas oportunidades aqui exploradas (duas passagens). Esse resultado é relevante, pois dá maior segurança àqueles interessados na caracterização espectral da vegetação ao longo do tempo.

\section{AGRADECIMENTOS}

Os autores expressam seus sinceros agradecimentos à empresa Fibria que permitiu acesso à área de estudo, a dados de inventário e pela disposição de pessoal e de transporte para os trabalhos em campo.

\section{REFERÊNCIAS}

CAMPOS, R. C. Modelo de transferência radiativa para dosséis descontínuos regulares (GRART): aplicações para dosséis de café. 2008. I57 p. Tese (Doutorado em Sensoriamento Remoto) - Instituto Nacional de Pesquisas Espaciais, São José dos Campos, 2008.

CANAVESI, V. Aplicação de dados Hyperion EO-I no estudo de plantios de Eucalyptus spp. 2008. 127 p. Tese (Doutorado em Sensoriamento Remoto) - Instituto Nacional de Pesquisas Espaciais, São José dos Campos, 2008.

CANAVESI, V.; PONZONI, F. J.; VALERIANO, M. M. Estimativa de volume de madeira em plantios de Eucalyptus spp. utilizando dados hiperespectrais e dados topográficos. Revista Árvore, Viçosa, v. 34, p. 539-549, 2010.

CHANDER, G.; MARKHAM, B. L.; HELDER, D. L. Summary of current radiometric calibration coefficients for Landsat MSS, TM, ETM+, and EO-I ALI sensors. Remote Sensing of Environment, New York, v. I I3, n. 5, p. 893-903, May 2009.

CRIST, E. P.; CICONE, R. C. A physically-based transformation of Thematic Mapper data- the TM Tasseled Cap. IEEE Transactions on Geoscience and Remote Sensing, New York, v. GE-22, n. 3, p. 256-263, 1984.

EMPRESA BRASILEIRA DE PESQUISA AGROPECUÁRIA. Centro Nacional de Pesquisa de Solos. Sistema brasileiro de classificação de solos. Brasília: EMBRAPA Produção de Informação; Rio de Janeiro: EMBRAPA Solos, 1999. 412 p.

FOODY, G. M.; BOYD, D. S.; CUTLER, M. E. J. Predictive relations of tropical forest biomass from Landsat TM data and their transferability between regions. Remote Sensing of Environment, New York, v. 85, n. 4, p. 463474, June 2003. 
HAY, J. E. Calculating solar radiation for inclined surfaces: practical approaches. Renewable Energy, Oxford, v. 3, n. 4/5, p. 373380, 1993.

HOUBORG, R.; SOEGAARD, H.; BOEGH, E. Combining vegetation index and model inversion methods for the extraction of key vegetation biophysical parameters using Terra and Aqua MODIS reflectance data. Remote SensingofEnvironment, New York, v. 106, n. I, p. 39-58, Jan. 2007.

PONZONI, F. J.; SHIMABUKURO, Y. E.; KUPLICH, T. M. Sensoriamento remoto da vegetação. São José dos Campos: Oficina de Textos, 2012. 135 p.

SCHLERF, M.; ATZBERGER, C. Inversion of a forest reflectance model to estimate structural canopy variables from hyperspectral remote sensing data. Remote Sensing of Environment, New York, v. 100, n. 3, p. 28I-294, Feb. 2006.
SOUZA, A. A. Estudo de fitofisionomias de Cerrado com dados do sensor Hyperion/EO-I. 2009. 120 p. Dissertação (Mestrado em Sensoriamento Remoto) Instituto Nacional de Pesquisas Espaciais, São José dos Campos, 2009.

VALERIANO, M. M. Equação para o cálculo do fator de iluminação. São José dosCampos: INPE, 2006.

VALERIANO, M. M. Modelo digital de elevação com dados SRTM disponíveis para a América do Sul. São José dos Campos: INPE, 2004. 72 p. (INPE-I0550-RPQ/756).

VERMOTE, E. F.; TANRE, D.; DEUZE, J. L.; HERMAN, M.; MORCRETTE, J. J. Second simulation of the satellite signal in the solar spectrum, 6S: an overview. IEEE Transactions on Geoscience and Remote Sensing, New York, v. 35, n. 3, p. 675-686, May 1997. 